\title{
OPTIMIZATION OF NFC ANTENNA TO MICROCONTROLLER'S BOARD DIMENSIONS
}

\author{
Tomáš LENGER, Alena PIETRIKOVÁ \\ Department of Technologies in Electronics, Faculty of Electrical Engineering and Informatics, \\ Technical University of Košice, Letná 9, 04200 Košice, Slovak Republic, tel. +421 55602 3011, E-mail: tomas.lenger@tuke.sk
}

\begin{abstract}
This paper is focused on Near-Field Communication (NFC), which is one of the most popular wireless communication. Although the NFC was developed in recent years, it is inseparable part of the everyday activities. NFC antenna is the key element for the realization of the NFC. This paper deals with the design of the miniaturized NFC antenna. Basic equations for coil inductance calculation, which are necessary for the NFC antenna design are presented as well. This paper also focuses on the influence of the coil's aspect ratio to its inductance. The aim of this paper was the optimization of the NFC antenna dimensions. NFC antenna dimensions were calculated according to dimension of microcontroller Printed Circuit Board (PCB), so the antenna can be laminated directly to microcontroller PCB.
\end{abstract}

Keywords: NFC, NFC antenna, antenna design

\section{INTRODUCTION}

Development of the industry is passing through the technological evolution called Industry 4.0. Industry 4.0 is based on merging electronics and informatics for higher efficiency of production process and for the convenience. This evolution is also focused on wireless communication between all electronic devices. There are many types or wireless communication with different features, which are currently used in electronics [1-6, 16, 19].

Wireless communications became very popular in the last decades because the wireless communications bring great convenience to many applications areas like sensors, energy harvesting, or commerce. The number of wireless communications devices is rapidly growing and has great potential for these real-world applications. Wireless communications also make electronic devices more robust because these types of communications reduce the risk of connection's degradation. Wireless communications, which additionally enable the power transfer becoming the most popular especially in sensors area [3-4, 6-7, 9].

NFC is one of the progressive possibilities for the wireless communication. NFC is wireless communication developed in recent decades, which takes irreplaceable place in everyday activities. NFC passed through the biggest growth due to its implementation into contactless paying methods. NFC represents low-power wireless data transmitting as well as wireless energy transfer. The advantage of the NFC is also its safety thanks to short communication range, which is less than $10 \mathrm{~cm}$. The number of NFC devices is rapidly growing, especially thanks to its application in paying methods. Nowadays, most of the smartphones supports this technology as well. NFC technology has also great potential for application in sensors or energy harvesting technique [1-3, 10-14].

Furthermore, the development of the electronics leads also to miniaturization of electronic devices. Electronic devices becoming more complex and offers many different features. The development is putting pressure to designing the miniaturized electronic devices with high connectivity with other electronic devices, mainly by the wireless communications. This leads to requirement for miniaturization of the antennas as well [7-11].

NFC antennas represent the key element for the realization of the NFC. NFC antennas are non-standard type of antennas and consist of LC circuit resonant at frequency $13.56 \mathrm{MHz}$. The shape of the antenna's coil affects the quality of the NFC transmission because the shape and dimensions of the antenna's coil influence its inductance. Planar coils for NFC antennas may be circular or rectangular [16-17].

Shape of the antenna should be optimized according to the shape of the PCB. There are many evaluation boards, which offers high performance and high connectivity to other electronic devices, but this boards usually don't include the NFC antenna. NFC antennas are usually available as add-on modules, which unfortunately markedly increase the dimensions of the final module [16$18]$.

Implementation of the NFC antenna directly on the microcontroller board seems like more effective possibility for miniaturization. However, the dimensions of the NFC antenna must be optimized to the dimensions of the microcontroller's board. Microcontroller's boards are mostly the rectangular shape, so the planar rectangular coils offer better utilization of the PCBs area than planar circular coils $[1,5,18]$.

This paper analyses possibilities of the NFC antenna's dimensions and shape optimization according to dimensions and shape of the microcontroller's board. This optimization considers the technological possibilities of multilayer interconnections as well. Our previous research shows that multilayer prepreg's core offers very good adhesion between microcontroller's board and NFC antenna's board.

There are many commercially available NFC antennas with different dimensions, but there NFC antennas were not optimized to dimensions of the microcontroller boards. This paper represents the optimization of the NFC antenna dimensions and shape that fit to microcontrollers' boards. XMC2Go microcontroller board with dimensions $38.5 \times 14$ $\mathrm{mm}$ was used for our research. Inductance of the antenna's coil must be considered during the NFC antenna design. 
This paper also focuses on the influence of the coil's aspect ratio to its inductance.

\section{EQUATIONS FOR RECTANGULAR NFC ANTENNA DESIGN}

NFC operates at frequency $13.56 \mathrm{MHz}$, so the resonance frequency of the NFC antenna (LC resonance circuit) must be the same. Fig. 1 shows the basic circuit for the NFC technology as well as equivalent circuit of the NFC antenna. Therefore, this paper focuses on the optimization of the rectangular NFC antenna dimensions to dimensions of the microcontroller board. Target inductance of the antenna coil is between 1.5 and $2.5 \mu \mathrm{H}[1,8,17]$.

a)

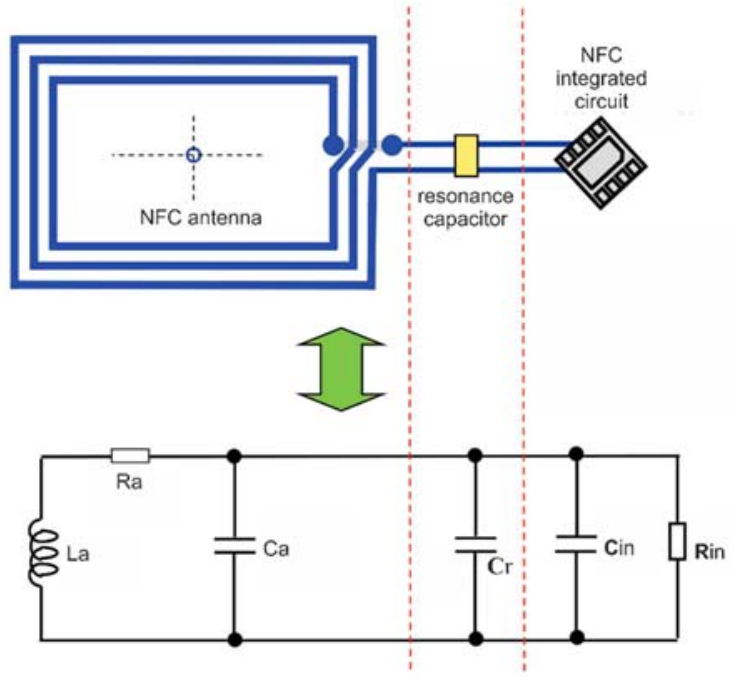

Fig. 1 NFC tag:

a) circuit of NFC tag

b) equivalent circuit of the NFC antenna [17]

NFC tag represents the simplest NFC circuit. NFC tag is passive NFC circuit, consisting of NFC antenna and NFC integrated circuit. Resonance frequency of this equivalent circuit (Fig. 1) is given by equation [17]:

$$
f_{r}=\frac{1}{2 \times \pi \times \sqrt{L_{a} \times\left(C_{a}+C_{r}+C \mid\right)}}
$$

where $f_{r}$ is resonance frequency, $L_{a}$ is inductance of the coil, $\mathrm{C}_{\mathrm{a}}$ is the parasite capacitance of the coil, $\mathrm{C}_{\mathrm{in}}$ is the capacitance of the NFC integrated circuit and $\mathrm{C}_{\mathrm{r}}$ is the capacitance of the resonance capacitor.

Resonance frequency has to be $13.56 \mathrm{MHz}$, so the capacitance of the resonance capacitor is given by equation [17]:

$$
C_{r}=\frac{1}{4 \times \pi^{2} \times L_{a} \times f_{r}^{2}}-\left(C_{a}+C\right)
$$

Inductance of the rectangular coil is defined by its dimensions (Fig. 2)

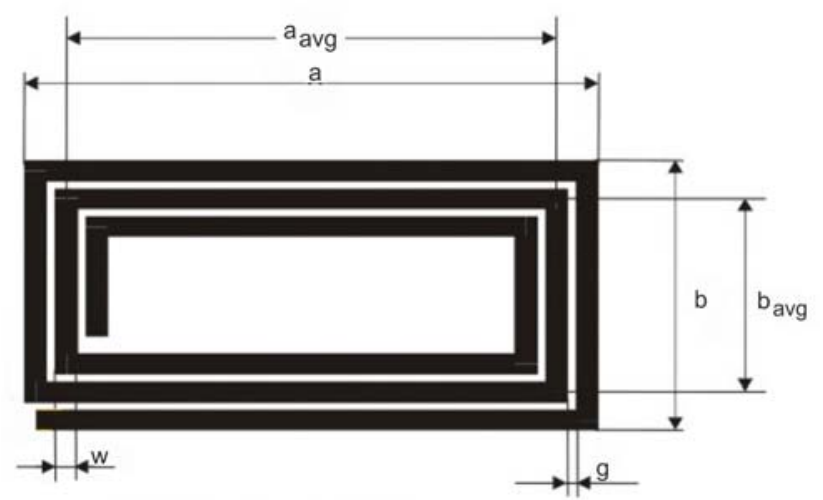

Fig. 2 Basic parameters of coil used for the coil inductance calculation [15]

Rectangular coil with two or more windings has to be recalculated to equivalent coil with one winding.

Equivalent diameter of the coil winding is given by equation [15]:

$$
d_{e q}=2 \times \sqrt{\frac{t \times w}{\pi}}
$$

where $\mathrm{t}$ is thickness of the winding, $\mathrm{w}$ is width of the winding and $\mathrm{d}_{\mathrm{eq}}$ is equivalent diameter of the winding.

Average length of the coil is given by equation [15]:

$$
a_{\text {avg }}=\sqrt{\frac{a^{2}+[a-2 N \times(g+w)]^{2}}{2}}
$$

where a is length of the outside coil winding, $\mathrm{N}$ is number of coil's turns, $g$ is isolation gap, $w$ is width of the winding and $a_{\text {avg }}$ is average length of the coil.

Average width of the coil is given by equation [15]:

$$
b_{a v g}=\sqrt{\frac{b^{2}+[b-2 N \times(g+w)]^{2}}{2}}
$$

where $\mathrm{b}$ is width of the outside coil winding, $\mathrm{N}$ is number of coil's turns, $g$ is isolation gap, $w$ is width of the winding and $b_{\text {avg }}$ is average width of the coil.

Equivalent coil with one winding is then used to calculate mutual and self-inductance of the coil parts. Mutual inductances of coil parts are given by equations [15]:

$$
\begin{aligned}
& M_{1}=\frac{\mu_{0}}{2 \pi}\left[a_{a v g} \times\right. \\
& \times \ln \left[\frac{2 \times a_{a v g} \times b_{a v g}}{d_{e q} \times\left(a_{a v g}+\sqrt{a_{a v g}{ }^{2}+b_{a v g}^{2}}\right)}\right]- \\
& \left.-2 b_{a v g}+\sqrt{{a_{a v g}}^{2}+b_{a v g}^{2}}\right]
\end{aligned}
$$




$$
\begin{aligned}
& M_{2}=\frac{\mu_{0}}{2 \pi}\left[b_{\text {avg }} \times\right. \\
& \times \ln \left[\frac{2 \times a_{a v g} \times b_{a v g}}{d_{e q} \times\left(b_{a v g}+{\sqrt{a_{a v g}^{2}+b_{a v g}^{2}}}^{2}\right.}\right]- \\
& \left.-2 a_{a v g}+\sqrt{{a_{a v g}{ }^{2}+b_{a v g}}^{2}}\right]
\end{aligned}
$$

where $\mu_{0}$ is vacuum permeability, $a_{\text {avg }}$ is coil average length, $b_{\text {avg }}$ is coil average width, $\mathrm{d}_{\mathrm{eq}}$ is equivalent diameter of the coil and $\mathrm{M}_{1} / \mathrm{M}_{2}$ are mutual inductance of the parallel coil parts. [15]:

Self-inductances of coil parts are given by equations

$$
\begin{aligned}
& L_{1}=\frac{\mu_{0} \times a_{a v g}}{16 \pi} \\
& L_{2}=\frac{\mu_{0} \times b_{\text {avg }}}{16 \pi}
\end{aligned}
$$

where $\mu_{0}$ is vacuum permeability, $a_{\text {avg }}$ is coil average length, $b_{\text {avg }}$ is coil average width and $\mathrm{L}_{1} / \mathrm{L}_{2}$ are selfinductance of parallel coil parts.

Inductance of the coil is given by equation [15]:

$$
L_{a}=\left(2 M_{1}+2 M_{2}+2 L_{1}+2 L_{2}\right) \times N^{E}
$$

where $\mathrm{M}_{1} / \mathrm{M}_{2}$ are mutual inductance of the coil parts, $\mathrm{L}_{1} / \mathrm{L}_{2}$ are self-inductance of the coil parts, $\mathrm{N}$ is number of the coil turns and $\mathrm{E}$ is fitting parameter of the coil.

\section{NFC ANTENNA CALCULATION - RESULTS AND DISCUSSION}

The main purpose of this paper is to miniaturize the NFC antenna dimensions according to dimensions of microcontroller board XMC2Go $(14 \mathrm{~mm} \times 38.5 \mathrm{~mm})$. $\mathrm{XMC2Go}$ board is high performance PCBA with programmable microcontroller. NFC antenna and XMC2Go combination creates the NFC communication module with high potential for different applications.

Table 1 shows input parameters for NFC antenna calculation. Equivalent parameters calculation of rectangular coil with more than one winding is the first step of the inductance calculation.

Table 1 Input parameters for the rectangular coil's inductance calculation

\begin{tabular}{|c|c|c|c|c|c|c|}
\hline $\begin{array}{c}\mathrm{T} \\
{[\mu \mathrm{m}]}\end{array}$ & $\begin{array}{c}\mathbf{w} \\
{[\mu \mathrm{m}]}\end{array}$ & $\begin{array}{c}\mathbf{g} \\
{[\mu \mathrm{m}]}\end{array}$ & $\begin{array}{c}\mathbf{a} \\
{[\mathbf{m m}]}\end{array}$ & $\begin{array}{c}\mathbf{b} \\
{[\mathbf{m m}]}\end{array}$ & $\mathbf{N}$ & $\mathbf{E}$ \\
\hline 35 & 200 & 150 & 30 & 13 & 7 & 1.75 \\
\hline
\end{tabular}

Equivalent diameter of the coil is calculated by substitution to Eq. 3:

$$
\begin{aligned}
& d_{e q}=2 \times \sqrt{\frac{3.5 \times 10^{-5} \times 2 \times 10^{-4}}{\pi}} \\
& d_{e q}=9.4407 \times 10^{-5} \mathrm{~m}
\end{aligned}
$$

Equivalent length and width of the coil are then calculated by substitution to Eq. 4 and Eq. 5 :

$$
\begin{aligned}
& a_{\text {avg }}=\sqrt{\frac{0.03^{2}+\left[0.03-2 \times 7 \times\left(3.5 \times 10^{-4}\right)\right]^{2}}{2}} \\
& a_{\text {avg }}=0.0276587 \mathrm{~m}
\end{aligned}
$$

$$
\begin{aligned}
& b_{\text {avg }}=\sqrt{\frac{0.013^{2}+\left[0.013-2 \times 7 \times\left(3.5 \times 10^{-4}\right)\right]^{2}}{2}} \\
& b_{\text {avg }}=0.0108307 \mathrm{~m}
\end{aligned}
$$

Calculated equivalent coil is used for inductance calculation. Mutual inductances of equivalent coil are calculated by substitution to Eq. 6 and Eq. 7 :

$$
\begin{aligned}
& M_{1}=\frac{4 \pi \times 10^{-7}}{2 \pi} \times\left[0.0276587 \times \ln \left[\frac{1}{9.4407 \times 10^{-5}} \times\right.\right. \\
& \left.\times \frac{2 \times 0.0276587 \times 0.0108307}{\left(0.0276587+\sqrt{0.0276587^{2}+0.0108307^{2}}\right)}\right]- \\
& \left.-2 \times 0.0108307+\sqrt{0.0276587^{2}+0.0108307^{2}}\right] \\
& M_{1}=2.764213501 \times 10^{-8}
\end{aligned}
$$

$$
\begin{aligned}
& M_{2}=\frac{4 \pi \times 10^{-7}}{2 \pi} \times\left[0.0108307 \times \ln \left[\frac{1}{9.4407 \times 10^{-5}} \times\right.\right. \\
& \left.\times \frac{2 \times 0.0276587 \times 0.0108307}{\left(0.0108307+\sqrt{0.0276587^{2}+0.0108307^{2}}\right)}\right]-
\end{aligned}
$$

$-2 \times 0.0276587+\sqrt{0.0276587^{2}+0.0108307^{2}}$

$$
M_{2}=5.823866087 \times 10^{-9}
$$

Self-inductances of equivalent coil are calculated by substitution to Eq. 8 and Eq. 9:

$$
\begin{aligned}
& L_{1}=\frac{4 \pi \times 10^{-7} \times 0.0276587}{16 \pi} \\
& L_{1}=6.914675 \times 10^{-10} \\
& L_{2}=\frac{4 \pi \times 10^{-7} \times 0.0108307}{16 \pi}
\end{aligned}
$$

$L_{2}=2.707675 \times 10^{-10}$

Inductance of the coil is then calculated by substitution to Eq. 10:

$$
\begin{aligned}
& L_{a}=2 \times\left(2.169052635 \times 10^{-8}+\right. \\
& +1.285411691 \times 10^{-8}+5.4222 \times 10^{-10}+ \\
& \left.+3.93545 \times 10^{-10}\right) \times 7^{1.75} \\
& L_{a}=2.074275 \mu H \\
& L_{a} \approx 2.07 \mu H
\end{aligned}
$$


Table 2 Calculated coils' parameters for rectangular NFC antenna

\begin{tabular}{|c|c|c|c|}
\hline $\mathrm{a}[\mathrm{mm}]$ & $\mathrm{b}[\mathrm{mm}]$ & $\mathrm{L}[\mu \mathrm{H}]$ & $\mathrm{S}\left[\mathrm{mm}^{2}\right]$ \\
\hline 21 & 21 & 2.09 & 441 \\
\hline 24 & 18 & 2.08 & 432 \\
\hline 30 & 15 & 2.23 & 450 \\
\hline 32 & 14 & 2.27 & 448 \\
\hline 34 & 13 & 2.31 & 442 \\
\hline 30 & 13 & 2.07 & 390 \\
\hline 35 & 10 & 2.09 & 350 \\
\hline
\end{tabular}

Table 2 shows the influence of the coil's shape on the inductance of the coil. This paper is focused on influence of the coil shape, so the winding's thickness, winding's width, isolation gap and number of turns were same for every designed coil. Coil's length (a) range was from 21 to $35 \mathrm{~mm}$. Coil's length $21 \mathrm{~mm}$ represents the reference squarish coil with required inductance. The aim was increasing of this dimension according to length of the microcontroller board. Coil's width (b) range was from 10 to $21 \mathrm{~mm}$. Coil's width $21 \mathrm{~mm}$ represents the reference squarish coil again, but there was requirement for decreasing of this parameter according to width of the microcontroller board. Only these two parameters variables during the calculation. The aim was comparison of the different coil's shapes and its influence on coil's inductance.

Squarish coil with length $21 \mathrm{~mm}$ (aspect ratio 1:1) cover area $441 \mathrm{~mm}^{2}$ and has inductance $2.09 \mu \mathrm{H}$. Rectangular antenna with aspect ratio 1.33:1 and dimensions $24 \times 18$ mm covering comparable area as the squarish coil and has also almost the same inductance. However, rectangular coil's with aspect ratio 2.61:1 and dimensions $34 \times 13 \mathrm{~mm}$ inductance increases to $2.31 \mu \mathrm{H}$ and covered area stays the same. Therefore, there is possibility for miniaturization of coil's dimensions as well as coil area by increasing the aspect ratio. Rectangular coil with dimensions $30 \times 13 \mathrm{~mm}$ and aspect ratio 2.3:1 allows the coil's miniaturization of more than $11 \%$ compared to squarish coil with the same inductance. Coil with dimensions $30 \times 13 \mathrm{~mm}$ and aspect ratio $2.3: 1$ is the most suitable to dimensions of the $\mathrm{XMC} 2 \mathrm{Go}$ microcontroller board as well.

Resonance frequency of the NFC antenna is than tuned by the resonance capacitor. Required capacitance of the capacitor for the resonance frequency $f_{r}=13.56 \mathrm{MHz}$ is calculated by substitution to Eq. 2 . Input capacitance of the $\mathrm{NFC}$ integrated circuit (NTAG $\mathrm{I}^{2} \mathrm{C}$ ) is $50 \mathrm{pF}$. NTAG $\mathrm{I}^{2} \mathrm{C}$ integrated circuit will be used for realization of the $\mathrm{NFC}$ module in future research.

$$
\begin{aligned}
& C_{r}=\frac{1}{4 \pi^{2} \times 2.07 \times 10^{-6} \times\left(13.56 \times 10^{6}\right)^{2}}-5 \times 10^{-11} \\
& C_{r} \approx 16 p F
\end{aligned}
$$

Calculated parameters represent the miniaturized NFC antenna, which is optimized for the dimensions of the XMC2Go microcontroller board. Fig. 3 shows the comparison of standard NFC antenna and miniaturized NFC antenna.
Figure 3 shows comparison of the commercially available NFC antenna (a) and NFC antenna optimized according to dimensions of the microcontroller board (b).

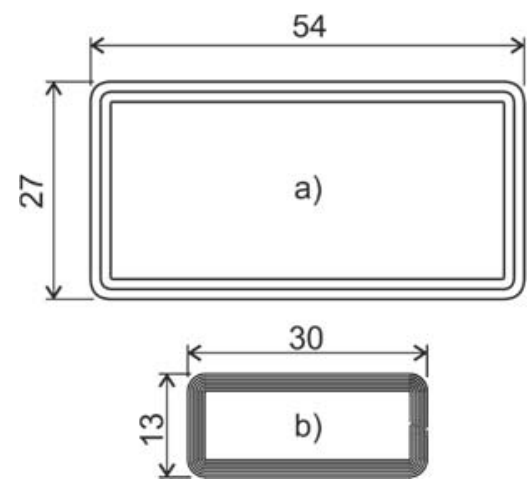

Fig. 3 Comparison of NFC antennas dimensions: a) commercially available NFC antenna b) optimized NFC antenna

Designed NFC antenna was manufactured and laminated to microcontroller (Fig. 4) by two-step lamination presented in [7]. There was not any shielding used. NFC module allowed communication between microcontroller and smartphone, but the antenna's influence on components assembled on microcontroller's board was not analyzed.

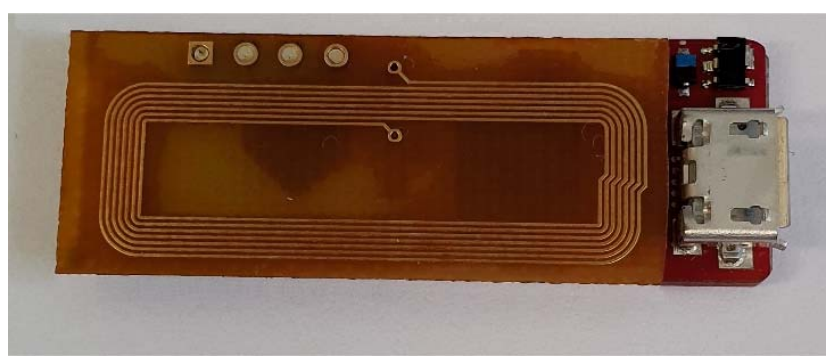

Fig. 4 Laminated NFC module

\section{CONCLUSIONS}

This paper was focused on dimensions' optimization of the miniaturized NFC antenna. NFC antenna was miniaturized to $30 \mathrm{~mm} \times 13 \mathrm{~mm}$ according to dimensions of XMC2Go microcontroller board. Designed NFC antenna and $\mathrm{XMC} 2 \mathrm{GO}$ microcontroller board was used for manufacturing of the NFC module. This paper includes calculation of NFC antenna, which can be used for design of NFC antenna with any dimensions. There is the possibility for even higher level of miniaturization, but it is not needed because of the dimensions of the XMC2Go microcontroller board. Inductance of the antenna's coil is directly influenced by the aspect ratio. The adequate aspect ratio of the antenna coil may decrease the area of the coil by $20 \%$, compared to area covered by squarish coil with the same inductance.

\section{ACKNOWLEDGMENTS}

This paper was supported by the project KEGA 017TUKE-4/2020 and project NFP 313011T557 Support for Research-Development Potential. 


\section{REFERENCES}

[1] COSKUN, V. - OZDENIZCI, B. - OK, K.: A Survey on Near Field Communication (NFC) Technology. 2013 Wireless personal communications, 71(3), 2259-2294.

[2] CHUNG, M. - CHIEM, Y. et al.: A dual-mode antenna for wireless charging and Near Field Communication. In Proceedings of the 2015 IEEE International Symposium on Antennas and Propagation USNC/URSI National Radio Science Meeting, Vancouver, Canada, 19-24 July 2015, pp. 1288-1289.

[3] OPPERMAN, C.A. - HANCKE, G.P.: Using NFCenabled phones for remote data acquisition and digital control. Proceedings of the IEEE Africon '11, Livingstone, Zambia, 13-15 September 2011, pp. 16.

[4] WIKNER, J.J. - ZÖTTERMAN, J. - JALILI, A. FARNEBO, S.: Aiming for the cloud-A study of implanted battery-free temperature sensors using NFC. In Proceedings of the 2016 International Symposium on Integrated Circuits (ISIC), Singapore, Singapore, 12-14 December 2016, pp. 1-4.

[5] CAO, Z. - CHEN, P. et al.: Near-field communication sensors. 2019. In Sensors. ISSN:1424-3210

[6] RAHIMI, R. - BRENER, U. - OCHOA, M. - ZIAIE, B.: Flexible and transparent $\mathrm{pH}$ monitoring system with NFC communication for wound monitoring applications. In Proceedings of the 2017 IEEE 30th International Conference on Micro ElectroMechanical Systems (MEMS), Las Vegas, USA, 22-26 January 2017, pp. 125-128.

[7] LENGER, T. - PIETRIKOVA, A. - LIVOVSKY, L. Nonstandard unidirectional lamination for Face down technology. In: ElectroScope: online časopis pro elektrotechniku. Roč. 2019, č. 2, pp. 1-4 [online]. ISSN 1802-4564

[8] DU, H.: NFC technology: Today and tomorrow. In International Journal of Future Computer and Communication, 2013, vol. 2, pp. 351.

[9] MARCUS, A. - DAVIDZON, D. et al.: Using NFCenabled mobile phones for public health in developing countries. In Institute of Electrical and Electronics Engineers, pp, 30-35, 2009.

[10] OK, K. - AYDIN, N. - COSKUN, V. - OZDENIZCI, B.: Exploring underlying values of NFC applications. In Proceedings of the Third International Conference on Information and Financial Engineering, Singapore, 2011, pp. 290-294.

[11] KIM, J. - BANKS, A. et al.: Miniaturized Flexible Electronic Systems With Wireless Power and Near $\square$ Field Communication Capabilities. In Advanced Functional Materials, 2015, vol. 25, pp. 4761-4767.

[12] LI, W. - LIANG, D. et al.: Low-cost miniaturized NFC antenna design for mobile phone. In Applied
Computational Electromagnetics Society Journal vol. 34(7), pp. 1043-1049.

[13] ZHAO, Y. - LI, H. et al.: Low-cost wireless power efficiency optimization of the NFC tag through switchable receiver antenna. In Wireless Power Transfer, 2018, vol. 5(2), pp. 87-96.

[14] XU, L. L. - LI, Y. et al.: A review on wearable NFC antenna devices. In Textile Bioengineering and Informatics Symposium Proceedings 2017 - 10th Textile Bioengineering and Informatics Symposium, TBIS 2017, pp. 131-145.

[15] GROVER, W. F. - ROSA, B. E.: Inductance Calculations: Working Formulas and Tables, Dover Publications, New York, 1946

[16] LUNTOVSKY, A. - GLOBA, L.: Performance, Reliability and Scalability for IoT. In Proceedings of the International Conference on Information and Digital Technologies 2019, pp. 316-321

[17] BIENERT, R.: Process For Designing an NFC Reader Application, 2017 , https:/community.nxp.com/t5/Connects-TrainingMaterial/Process-for-Designing-an-NFC-ReaderApplication/ta-p/1113146?attachment-id=14866

[18] Infineon: XMC 2Go Datasheet, 2014, https://www.infineon.com/dgdl/Board_Users_Manua 1_XMC_2Go_Kit_with_XMC1100_R1.0.pdf? fileId= $\overline{\mathrm{db}} 3 \mathrm{a} 30 \overline{43444 \overline{\mathrm{e}} \mathrm{e}} \overline{\mathrm{dc}} 014 \overline{4} 53 \mathrm{~d} 6 \mathrm{c} 7507 \overline{8} \mathrm{c} 6$

[19] POOR, P. - BASL, J. - ZENISEK, D.: Predictive Maintenance 4.0 as next evolution step in industrial maintenance development. In 2019 International Research Conference on Smart Computing and Systems Engineering, SCSE 2019, pp. 245-253.

Received January 21, 2021, accepted May 26, 2021

\section{BIOGRAPHIES}

Tomáš Lenger was born on 1993. In 2017 he graduated (MSc) at the Department of Technologies in Electronics of the Faculty of Electrical Engineering and Informatics at Technical University of Košice. Now, he is a PhD. student at the same department. His scientific research is focused on embedded components in electronic and applying the embedded components into NFC module.

Alena Pietriková is a professor and the Head of Department of Technologies in Electronics, Technical University of Kosice, Slovakia. She receives her M.Sc. in material science in 1980 and Ph.D. in 1986 at Technical University of Košice, Slovakia. Currently the main subject of her research is thick-film technologies, assembling technologies in electronics and materials for electronics. She is co-author of more than 320 scientific publications, (more than 80 indexed in the WoS database). 